\title{
Detection of optic disc change with the Heidelberg retina tomograph before confirmed visual field change in ocular hypertensives converting to early glaucoma
}

\author{
D S Kamal, A C Viswanathan, D F Garway-Heath, R A Hitchings, D Poinoosawmy, \\ C Bunce
}

However, it has been widely reported that clinically detectable glaucomatous change in the optic disc may precede the onset of white on white visual field defects by up to several years. ${ }^{1-6}$ An explanation for this observation may be seen in the results of a postmortem histological study demonstrated that up to $40 \%$ of nerve fibres may be lost from the optic disc before the development of visual field defects in patients with ocular hypertension. ${ }^{7}$

One of the difficulties in identifying conversion from OHT to early glaucoma is the high level of variability in performance that affects automated perimetry. This has been well documented in both normal subjects and glaucoma patients, with higher levels of both intratest and intertest fluctuation seen in the latter group. ${ }^{89}$ For this reason, many accept that a field defect should be reproduced on more than two consecutive reliable visual fields before it can be said that it is actually confirmed. ${ }^{8}{ }^{10}$ Because patients with glaucoma or ocular hypertension may also show less reliability in the performance of visual field tests than normal controls, ${ }^{11}$ the length of time in between the first visual field, and the final confirming visual field demonstrating a scotoma may be considerable, potentially delaying the diagnosis of glaucoma.

Controlling the intraocular pressure (IOP) at an early stage in glaucoma has been shown to slow down or stop progression of the disease, ${ }^{12-14}$ and at the present time IOP manipulation is the only practical therapeutic option available. It is the desire of all ophthalmologists to detect the presence of glaucomatous damage in a patient as early as possible so that treatment can be offered at the outset. This may be delayed if diagnosis is made on the basis of the development of a reproducible visual field defect. The alternative method of detection of glaucomatous change by the analysis of optic disc variables may give us a more objective means of assessment than the currently available methods of visual field analysis. $^{\circ}$

The Heidelberg retina tomograph (HRT Heidelberg Engineering, Heidelberg, Germany) has been widely investigated as a research tool in the imaging of the optic nerve head and its method of analysis has been described elsewhere. ${ }^{15}{ }^{16}$ The analysis of HRT images allows the quantitative measurement of three dimensional optic disc variables such as cup volume and rim volume. It has also been requires the presence of a glaucomat defect in conjunction with corresponding op disc or retinal nerve fibre layer defects.
Accepted for publication 30 September 1998 \begin{abstract}
coma.
(Br F Ophthalmol 1999;83:290-294)
\end{abstract}

Mr R A Hitching:

Glaucoma Unit, Moorfield

Eye Hospital, City Road,

The currently accepted definition of glau 
documented to have high levels of reproducibility and reliability of topographical variables. ${ }^{15} 17$ Image analysis on the HRT has been shown to produce optic disc measurements, such as the estimation of cup/disc area ratio, which are comparable to those made by clinicians. ${ }^{19}$ Several studies have demonstrated that the HRT may be used to differentiate between normal and glaucomatous eyes ${ }^{20-24}$ although, in some, considerable overlap of variable values between the groups has been found. Glaucomatous optic disc variables measured with the HRT have also been shown to correlate highly with visual field indices indicating glaucomatous change. ${ }^{25}$

The ocular hypertension (OHT) study has been conducted at Moorfields Eye Hospital $(\mathrm{MEH})$ over the past 5 years. The study is currently following a group of 291 medium to high risk $^{26}$ ocular hypertensive patients, a proportion of whom have developed early glaucomatous field loss during the follow up period. We have called this particular patient group the "converters". One of the aims of the study is to evaluate several pyschophysical and imaging techniques to determine their ability to detect early glaucomatous damage. For this purpose, all patients on the study have undergone serial HRT optic disc imaging since 1994, when the equipment first became available to us. A group of normal controls undergo similar investigations in order to compare their results with those of the patients on the study. The aim of this part of the study was to determine whether the analysis of sequential SLO images with the HRT could demonstrate glaucomatous change in the optic disc variables of the group of converters, before the confirmation of glaucomatous field defects.

\section{Methods \\ SUBJECTS \\ OHT patients}

The OHT study was approved by the ethics committee at $\mathrm{MEH}$ and all patients and normal volunteers participating on the study gave their informed consent to participate on initial recruitment.

A number of OHT patients have converted to early glaucoma on the basis of AGIS visual field criteria, ${ }^{27}$ over the time course of the study. All visual field testing in our study is performed by means of the 24-2 threshold strategy on the type 1 (first generation) Humphrey field analyser. Initial eligibility criteria for entry into the trial included:

1 An IOP of $>21 \mathrm{~mm} \mathrm{Hg}$ on two or more occasions.

2 Two consecutive visual fields with an AGIS score of 0 .

3 Absence of any other ocular disease.

4 Age $>35$ years.

Optic disc appearance was not a restriction criterion.

The mean age of the converting group was 69.0 (SD 9.08) years.

For the purposes of the OHT study, we have defined conversion as the development of an AGIS score greater than or equal to 1 from an initial score of 0 , on three consecutive repro- ducible and reliable Humphrey 24-2 strategy visual fields, with at least one location consistently below the threshold for normality. A reliable field is obtained when the following AGIS criteria are met: $<25 \%$ fixation losses, $<30 \%$ false negative errors and $<30 \%$ false positive errors. Routine perimetric testing was carried out every 4 months but the protocol in the study dictates that if a patient develops a visual field defect then the test is repeated within 1 month, and if the same defect is then reproduced on a reliable second field, then a third test is performed 3-4 months after this. Conversion is confirmed if the field defect is present on the three consecutive reliable tests. If the defect is present but the reliability indices fall outside those described above, then the test is repeated again within 1 month. If a field defect is not reproduced on the second or third attempts, then a routine perimetric appointment is given for 4 months' time.

Each patient undergoes yearly optic disc imaging with the HRT.

A good quality mean topographical image was defined as one in which the optic disc morphology was clearly visible, with an overall standard deviation of less than $40 \mu \mathrm{m}$. Those converters with two consecutive good quality images taken with the HRT before the third conversion confirming visual field were included in the analysis.

\section{Normal controls}

The normal control patients were recruited by means of the following eligibility criteria:

1 IOP $<21 \mathrm{~mm} \mathrm{Hg}$ on two or more occasions.

2 Two consecutive visual fields with an AGIS score of 0 . Acceptable reliability indices of visual field performance were the same as for the OHT group.

3 No ocular disease.

4 No family history of glaucoma or ocular hypertension.

5 Age $>35$ years.

Optic disc appearance was not a restriction criterion.

The mean age of the normal group was 59.9 (SD 13.1) years.

Those normal controls who had two consecutive good quality images taken with the HRT were included in the analysis.

HRT IMAGING

For each HRT imaging session, three $10 \times 10$ degree SLO images were obtained for each eye by one of two experienced operators. Images with significant movement artefact were rejected. All analysis on the HRT was performed using HRT software version 1.11. The mean topography of the three images was generated and the disc edge was delineated on the mean image by a single observer (DK), using a mouse drawn contour line. The HRT software was used to analyse both global and segmental optic disc variables. The contour line was then exported from the first HRT mean image (SLO1) onto the second HRT mean image (SLO2) of the same optic disc.

The following optic disc variables were analysed directly by means of HRT software: disc 
Table 1 Summary of segmental and global cup variables showing significant change from SLO1 to SLO2 in converters

\begin{tabular}{|c|c|c|c|c|c|}
\hline & $\begin{array}{l}\text { Global cup } \\
\text { area } \\
\left(\mathrm{mm}^{2}\right)\end{array}$ & $\begin{array}{l}\text { Superonasal cup } \\
\text { area }\left(m m^{2}\right)\end{array}$ & $\begin{array}{l}\text { Global } \\
\text { C/D area } \\
\text { ratio }\end{array}$ & $\begin{array}{l}\text { Superonasal } \\
C / D \text { area ratio }\end{array}$ & $\begin{array}{l}\text { Inferonasal cup } \\
\text { vol }\left(\mathrm{mm}^{3}\right)\end{array}$ \\
\hline Direction of change & $\uparrow$ & $\uparrow$ & $\langle\uparrow$ & $\uparrow$ & $\uparrow$ \\
\hline SLO1 mean value & 0.786 & 0.086 & 0.429 & 0.351 & 0.019 \\
\hline SD & 0.305 & 0.048 & 0.127 & 0.155 & 0.015 \\
\hline Mean change & 0.076 & 0.010 & 0.050 & 0.041 & 0.005 \\
\hline SD & 0.113 & 0.014 & 0.066 & 0.053 & 0.008 \\
\hline \multicolumn{6}{|l|}{ Mean percentage } \\
\hline change & 9.7 & 11.0 & 10.5 & 11.7 & 28.4 \\
\hline p Value & 0.02 & 0.04 & 0.02 & 0.03 & 0.04 \\
\hline
\end{tabular}

Table 2 Summary of segmental and global rim variables showing significant change from SLO1 to SLO2 in converters

\begin{tabular}{lcclll}
\hline & $\begin{array}{l}\text { Temporal } \\
\text { rim vol } \\
\left(\mathrm{mm}^{3}\right)\end{array}$ & $\begin{array}{c}\text { Inferotemporal } \\
\text { rim vol }\left(\mathrm{mm}^{3}\right)\end{array}$ & $\begin{array}{l}\text { Global } \\
\text { rim area } \\
\left(\mathrm{mm}^{2}\right)\end{array}$ & $\begin{array}{l}\text { Superonasal } \\
\text { rim area } \\
\left(\mathrm{mm}^{2}\right)\end{array}$ & $\begin{array}{l}\text { Superotemporal } \\
\text { rim area }\left(\mathrm{mm}^{2}\right)\end{array}$ \\
\hline Direction of change & $\downarrow$ & $\downarrow$ & $\downarrow$ & $\downarrow$ & $\downarrow$ \\
SLO1 mean value & 0.016 & 0.022 & 1.018 & 0.151 & 0.119 \\
SD & 0.009 & 0.016 & 0.224 & 0.032 & 0.042 \\
Mean change & 0.003 & 0.005 & 0.070 & 0.010 & 0.008 \\
SD & 0.006 & 0.006 & 0.105 & 0.014 & 0.020 \\
$\begin{array}{l}\text { Mean percentage } \\
\quad \text { change }\end{array}$ & 15.6 & 23.6 & 6.9 & 6.6 & 6.9 \\
p Value & 0.04 & 0.01 & 0.03 & 0.02 & 0.04 \\
\hline
\end{tabular}

area, cup area, cup volume, rim volume, and third moment (cup shape measure) using the standard reference plane. Cup/disc (C/D) area ratio was calculated by dividing the cup area by the disc area. Rim area was calculated by subtracting the cup area from the disc area.

The following six optic disc segments were analysed: nasal, superonasal, inferonasal, temporal, superotemporal, inferotemporal. Global variables were also analysed.

STATISTICAL METHODS

The data for analysis were not distributed normally, therefore the non-parametric Wilcoxon signed rank statistical test (on sPSS for Windows, version 6.0) was used to determine if there were any statistically significant differences between the variable values for SLO1 and SLO2. A result was considered to be statistically significant if the $\mathrm{p}$ value $<0.05$.

The mean magnitude of change was determined by calculating the difference between each of the variable values for SLO1 and SLO2 for each subject and then averaging this for the whole group. This was then expressed as a percentage of the original mean variable value of

Table 3 Summary of results for cup variables in controls

\begin{tabular}{lccccc}
\hline & $\begin{array}{l}\text { Global } \\
\text { cup area } \\
\left(\mathrm{mm}^{2}\right)\end{array}$ & $\begin{array}{l}\text { Superonasal cup } \\
\text { area }\left(\mathrm{mm}^{2}\right)\end{array}$ & $\begin{array}{l}\text { Global C/D } \\
\text { area ratio }\end{array}$ & $\begin{array}{l}\text { Superonasal } \\
\text { C/D area ratio }\end{array}$ & $\begin{array}{l}\text { Inferonasal cup } \\
\text { vol }\left(\mathrm{mm}^{3}\right)\end{array}$ \\
\hline SLO1 mean value & 0.727 & 0.075 & 0.363 & 0.284 & 0.013 \\
SD & 0.063 & 0.062 & 0.012 & 0.159 & 0.016 \\
Mean change & -0.030 & -0.009 & -0.003 & -0.030 & -0.002 \\
SD & 0.218 & 0.023 & 0.081 & 0.062 & 0.006 \\
p Value & 0.70 & 0.18 & 0.60 & 0.09 & 0.61 \\
\hline
\end{tabular}

Table 4 Summary of results for rim variables in normal controls

\begin{tabular}{lclccc}
\hline & $\begin{array}{l}\text { Temporal } \\
\text { rim vol } \\
\left(\mathrm{mm}^{3}\right)\end{array}$ & $\begin{array}{l}\text { Inferotemporal } \\
\text { rim vol }\left(\mathrm{mm}^{3}\right)\end{array}$ & $\begin{array}{l}\text { Global } \\
\text { rim area } \\
\left(\mathrm{mm}^{2}\right)\end{array}$ & $\begin{array}{l}\text { Superonasal } \\
\text { rim area }\left(\mathrm{mm}^{2}\right)\end{array}$ & $\begin{array}{l}\text { Superotemporal } \\
\text { rim area }\left(\mathrm{mm}^{2}\right)\end{array}$ \\
\hline SLO1 mean value & 0.020 & 0.030 & 1.171 & 0.170 & 0.132 \\
SD & 0.006 & 0.014 & 0.153 & 0.036 & 0.025 \\
Mean change & -0.001 & 0.001 & -0.02 & -0.007 & -0.007 \\
SD & 0.007 & 0.009 & 0.201 & 0.020 & 0.027 \\
p Value & 0.81 & 0.58 & 0.31 & 0.46 & 0.60 \\
\hline
\end{tabular}

SLO1 for the group resulting in the mean percentage change value. The length of time between SLO2 and the third confirming visual field (VF3) was determined for each patient, and the median time calculated.

\section{Results}

In total, at the time of the HRT study, 16 OHT patients out of a total trial number of $291 \mathrm{had}$ converted to early glaucoma on the basis of AGIS criteria. Good quality sequential HRT images were obtained for 13 eyes of 13 converters. Of the three remaining converters, the images of one patient were not used in the analysis because they were of poor quality, and the other two were excluded because they had undergone the second SLO imaging after VF3.

The mean length of follow up of the patient group from the time of entry into the OHT trial to confirmed conversion was 32.6 (SD 13.67) months. The median time interval between SLO1 and SLO2 for the patient group was 12.0 months, and for the normal control group, 13.0 months.

The median number of months between SLO 2 and VF3 was 6.5 months.

In the patient group significant differences between the values of SLO1 and SLO2 were found for several optic disc variables and the results are set out in Tables 1 and 2 .

No significant differences between the values of the global and segmental variables of SLO1 and SLO2 were found for the control group of normal subjects. The control group mean differences between SLO1 and SLO2 values, for variables that were found to change in the converters are summarised in Tables 3 and 4, for comparison.

\section{Discussion}

The number of patients in this study was limited because of the number of patients who have so far converted from ocular hypertension to early glaucoma. Sixteen patients had undergone conversion at the time that the analysis was carried out, but only 13 of these had consecutive SLO images that were suitable to be used in the analysis.

Three global optic disc variables were found to change in the converters over time: cup area, $\mathrm{C} / \mathrm{D}$ area ratio, and rim area. These results correspond with what we would expect to observe in glaucomatous change..$^{28-30}$

The other significant results were found on segmental analysis of disc variables. Interestingly, the largest change in segmental values was found in the inferonasal cup volume as this segment is seldom associated with clinically observable change. The next largest change was found in the inferotemporal rim volume, a segmental variable documented to be the most common site of clinically detected early glaucomatous change. ${ }^{31}$ The results indicate that segmental as well as global analysis of optic disc images is required for detection of glaucomatous change, and suggest that the HRT may be able to detect change in areas such as the superonasal, inferonasal, and superotemporal segments which may not be detected clinically. 
It may be argued that by analysing several variables in several segments some significant results may be found simply by chance. However, no significant results were found in the normal control group using the same method of analysis. In addition, all the variables that changed did so in one direction. This was the direction one would expect for glaucomatous change.

The Wilcoxon statistical test is a nonparametric test that analyses data as a group rather than on an individual basis. The results obtained reflect the general direction of change, if present, for the group as a whole. Thus, for those segmental variables that did show change over time from SLO1 to SLO2, the majority of the optic discs within the group changed in that direction but a number remained stable, and some changed in the opposite direction. Therefore, in the analysis of the mean magnitude of change, the standard deviation values are large, reflecting the wide range of individual values within the group, and some have a negative value showing change in the opposite direction to the majority.

Variability in measured topographical variables may arise from variability in the contour line alignment when the contour line export facility is used..$^{32}$ This may contribute to some of the variability between SLO1 and SLO2 variable values, but not the overall direction of change.

Another possible criticism of the method used here is that the examiner was not masked to the subject group or time sequence of the optic disc images examined in the study, thus introducing a potential source of bias. However, we do not feel that the lack of masking would influence the results to a significant degree as once the initial contour line has been drawn around the disc edge, all further analysis including the export of the contour is fully automated by HRT software. The design of the equipment makes masking impossible as subject details are displayed along with each image on the screen.

A recent study ${ }^{25}$ which examined the correlation between visual field indices and HRT variables in glaucomatous patients found with multiple regression analysis that the neuroretinal rim area was the most important predictor of mean deviation and corrected pattern standard deviation values. Cup area, C/D area ratio, rim area, rim volume, third moment, and the retinal nerve fibre layer cross sectional area were also found to correlate with these indices. Other cross sectional studies have also found that the third moment may be of value in demonstrating group differences between normal, glaucomatous, and ocular hypertensive eyes. ${ }^{21-23}$ Third moment was not found to be useful in detecting change by longitudinal analysis of the same disc in our study. We have not included an analysis of the correlation between the location of the visual field defects and the location of optic disc change. The analysis method used in this study examined the data for each of the groups as a whole and therefore it would not be appropriate to exam- ine the position of the field defects for individual converters.

Optic disc appearance was not a restriction criterion for entry into the study for either the OHT group or the normal group. Subjects were therefore not chosen on the basis of their optic disc appearance, eliminating an important and often overlooked source of selection bias from our study. The SLO1 mean values for the cup measures in the converters were greater than the values for the normal group (see Tables 2 and 4). The wide range of cup variable values in the group of converters is reflected by the large standard deviations. Also, the mean values for the rim variables in SLO1 were less in the converting group than in the normal group (see Tables 3 and 4). This may be explained by the fact that a number of the converters had "glaucomatous optic discs" at the time of SLO1, despite having normal visual fields. In this group, the HRT was able to detect further glaucomatous change in an already abnormal disc, before the development of confirmed visual field loss.

One of the major challenges in the management of glaucoma is the early detection of disease. This study, although small scale, suggests that the HRT may be of use in detecting glaucomatous change in the optic nerve head over time before confirmed visual field change. Although other clinical methods have also demonstrated similar changes, this study provides, for the first time, actual measured data of optic disc changes. This allows quantification of the changes as well as the identification of the specific optic disc regions where it occurs. As more ocular hypertensives convert to early glaucoma on our study, then we will be able to further evaluate the HRT for this purpose. Further study has also been carried out using the data from sequential HRT images in a group of ocular hypertensives who have as yet shown no consistent VF abnormality. A number of these have been demonstrated to show glaucomatous optic disc change, and we hope to publish this work in the near future. Such work will allow us to investigate whether analysis of sequential optic disc images may be useful in predicting which individual patients with ocular hypertension are likely to develop visual field defects. Assessing optic disc change in the converting patient on an individual basis will also allow us to determine if there is a correlation between the location of disc change and the location of the scotoma. At the present time, the HRT is mainly a research tool, but if it proves a useful diagnostic aid in the management of the glaucoma or glaucoma suspect patient then its wider use in the clinical setting may be justified.

This study was supported by funds from the Guide Dogs for the Blind Association. Each author states that $\mathrm{s} / \mathrm{he}$ has no proprietary interest in the development or the marketing of the Heidelberg retina tomograph or any competing instrument. The authors would like to thank the OHT study technicians Ms Isabelle Antunes and Mr Ian Thrasher for their invaluable Ms Isabelle Antunes and Mr Ian Thrasher
help in the collection of data for the study.

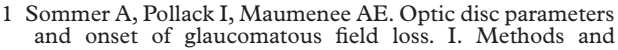
and onset of glaucomatous field loss. I. Methods and
progressive changes in disc morphology. Arch Ophthalmol progressive chang
1979;97:1444-8.
} 
2 Pederson JE, Anderson DR. The mode of progressive disc cupping in ocular hypertension and glaucoma. Arch

3 Caprioli J. Correlation of visual function with optic nerve and nerve fiber layer structure in glaucoma. Surv Ophthalmol 1989;33:319-30.

4 Tuulonen A, Airaksinen PJ. Initial glaucomatous optic disk and retinal nerve fiber layer abnormalities and their progression. Am f Ophthalmol 1991;111:485-90.

5 Zeyen TG, Caprioli J. Progression of disc and field damage in early glaucoma. Arch Ophthalmol 1993;111:62-5.

6 Caprioli J, Prum B, Zeyen T. Comparison of methods to evaluate the optic nerve head and nerve fiber layer for glaucomatous change. Am f Ophthalmol 1996;121:659-67.

7 Quigley HA, Addicks EM, Green WR. Optic nerve damage in human glaucoma. III. Quantitative correlation of nerve fiber loss and visual field defect in glaucoma, ischemic neuropathy, papilledema, and toxic neuropathy. Arch Ophthalropathy, papilledema,
mol $1982 ; 100: 135-46$.

8 Heijl A, Lindgren A, Lindgren G. Test-retest variability in glaucomatous visual fields. Am f Ophthalmol 1989;108: $130-5$.

9 Boeglin RJ, Caprioli J, Zulauf M. Long-term fluctuation of the visual field in glaucoma. Am f Ophthalmol 1992;113 396-400.

10 Schulzer M. Errors in the diagnosis of visual field progression in normal-tension glaucoma [see comments] Ophthalmology 1994;101:1589-94.

11 Katz J, Sommer A, Witt K. Reliability of visual field results over repeated testing. Ophthalmology 1991;98:70-7.

12 Mao LK, Stewart WC, Shields MB. Correlation between intraocular pressure control and progressive glaucomatous damage in primary open-angle glaucoma. Am $\mathcal{F} O$ phthalmol 1991;111:51-5.

13 Chauhan BC, Drance SM. The relationship between intraocular pressure and visual field progression in glaucoma. Graefes Arch Clin Exp Ophthalmol 1992;230: 521-6.

14 Migdal C, Gregory W, Hitchings R. Long-term functional outcome after early surgery compared with laser and medi-
cine in open-angle glaucoma. Ophthalmology 1994;101: cine in $1651-6$.

15 Cioffi GA, Robin AL, Eastman RD, et al. Confocal laser scanning ophthalmoscope. Reproducibility of optic nerve head topographic measurements with the confocal laser scanning ophthalmoscope. Ophthalmology 1993;100:5762.

16 Rohrschneider K, Burk ROW, Kruse FE, et al. Reproducibility of the optic nerve head topography with a new laser tomographic scanning device. Ophthalmology 1994;101: 1044-5.

17 Dreher AW, Tso PC, Weinreb RN. Reproducibility of topographic measurements of the normal and glaucomatous optic nerve head with the laser tomographic scanner. $A m \mathcal{F}$ Ophthalmol 1991;111:221-9.

18 Chauhan BC, LeBlanc RP, McCormick TA, et al. Test-retest variability of topographic measurements with confocal scanning laser tomography in patients with glaucoma and control subjects. Am f Ophthalmol 1994;118:9-15.

19 Zangwill L, Shakiba S, Caprioli J, et al. Agreement between clinicians and a confocal scanning laser ophthalmoscope in estimating cup/disk ratios. Am f Ophthalmol 1995;119:41521 .

20 Mikelberg FS, Parfitt CM, Swindale NV, et al. Ability of the Heidelberg retina tomograph to detect early glaucomatous field loss. F Glaucoma 1995;4:242-7.

21 Zangwill LM, van Horn S, De Souza Lima M, et al. Optic nerve head topography in ocular hypertensive eyes using confocal scanning laser ophthalmoscopy. Am f Ophthalmol 1996;122:520-5.

22 Uchida H, Brigatti L, Caprioli J. Detection of structural damage from glaucoma with confocal laser image analysis. Invest Ophthalmol Vis Sci 1996;37:2393-401.

23 Hatch WV, Flanagan JG, Etchells EE, et al. Laser scanning tomography of the optic nerve head in ocular hypertension and glaucoma. Br f Ophthalmol 1997;81:871-6.

24 Wollstein G, Garway-Heath D, Hitchings R. Identification of early glaucoma cases with the scanning laser ophthalmoscope. Invest Ophthalmol Vis Sci 1997 (Suppl).

25 Iester M, Mikelberg FS, Courtwright P, et al. Correlation between visual field indices and Heidelberg retina tomograph parameters. F Glaucoma 1997;6:78-82.

26 Yablonski ME, Zimmerman TJ, Kass MA, et al. Prognostic significance of optic disc cupping in ocular hypertensive patients. Am f Ophthalmol 1980;89:585-90.

27 AGIS investigators. Advanced glaucoma intervention study. Ophthalmology 1994;101:1445-55.

28 Armaly MF. The correlation between appearance of the optic cup and visual function. Trans Am Acad Ophthalmol Otol 1969;73:898-913.

29 Armaly MF. The optic cup in the normal and glaucomatous eye. Invest Ophthalmol Vis Sci 1970;9:425-9.

30 Airaksinen PJ, Drance SM. Neuroretinal rim area and retinal nerve fiber layer in glaucoma. Arch Ophthalmol 1985;103:203-4.

31 Jonas JB, Gusek GC, Naumann GO. Optic disc morphometry in chronic primary open-angle glaucoma. I. Morphometric intrapapillary characteristics. Graefes Arch Clin Exp Ophthalmol 1988;226:522-30.

32 Orgul S, Cioffi GA, Buskirk EMV. Variability of contour line alignment on sequential images with the Heidelberg retina tomograph. Graefes Arch Clin Exp Ophthalmol 1997;235: $82-6$ 